\title{
UMA PERSPECTIVA PSICANALÍTICA PARA A EDUCAÇÃO AMBIENTAL
}

\author{
Ana Lizete Farias ${ }^{1}$; Maria do Rosário Knechtel²
}

\section{RESUMO}

O debate sobre a crise ambiental tem ultrapassado as relações usuais com as ciências naturais e passaram a incluir novos saberes de diferentes disciplinas. É sabido que a psicanálise de Sigmund Freud operou uma ruptura com o saber existente produzindo seu próprio lugar. Como olhar a Educação Ambiental, então, a partir da psicanálise, que supõe um sujeito dividido, dominado pelas pulsões e sua implicação (ou não) na preservação da vida no planeta? Este trabalho propõe alguns elementos para essa discussão.

Palavras-chave: Educação Ambiental; Psicanálise Epistemologia; socioambiental.

\section{A PSYCHOANALYTIC PERSPECTIVE FOR THE ENVIRONMENTAL EDUCATION}

\section{ABSTRACT}

The discussion about the environmental crisis has exceeded the usual relations with the natural sciences and started to include new knowledge from different disciplines. It is well known that Sigmund Freud's psychoanalysis operated a rupture with existing knowledge producing its own place. How to look at Environmental Education, then, from psychoanalysis, which supposes a divided subject, dominated by the drives and their implication (or not) in the preservation of life on the planet? This paper proposes some elements for this discussion.

Keywords: Environmental Education; Psychoanalysis; Socio-environmental Epistemology.

\footnotetext{
1 Doutoranda no Programa de Meio Ambiente e Desenvolvimento da UFPR. Mestre em Geologia Ambiental pela UFPR. Bacharel em Geologia pela UFRS. Pesquisadora do Núcleo de Direito e Psicanálise da UFPR, Integrante do Grupo de Pesquisa "Epistemologia e Sociologia Ambiental" (CNPq). Email: analizete@gmail.com.

2 Doutora em Sociologia da Educação pela Universidade Federal de Santa Maria (UFSM), PósDoutora em Educação Permanente e a Distância pela Universidad Nacional de Educacíon a Distancia (UNED), na Espanha, e Pós-Doutora em Sociologia e Educação Ambiental pela Universidade de Berlim, Karlsruhe, na Alemanha. MSc em Ciências Sociais pela Universidade de São Paulo. Atualmente é professora e pesquisadora do Programa de PósGraduação em Meio Ambiente e Desenvolvimento da Universidade Federal do Paraná (UFPR). Email: mknechtel10@gmail.com.
} 


\section{Introdução}

Este trabalho é um recorte da tese de doutoramento em curso no Programa de Pós-Graduação em Meio Ambiente e Desenvolvimento, PPGMADE da Universidade Federal do Paraná UFPR que tem como fim realizar uma leitura psicanalítica, a partir de uma perspectiva freudiana, sobre a crise ambiental. Neste artigo tem como objetivo principal conceder algumas reflexões que contribuam para a construção de um diálogo entre a Psicanálise e a Educação Ambiental, tarefa que reconhecemos ser pouco fácil.

Partimos do pressuposto que há um verdadeiro mal-estar na crise ambiental, no sentido descrito por Freud (1930) o qual não se insurge contra, nem à revelia do processo civilizatório, mas é diretamente oriundo deste. Nas palavras de Floriani (2004): "O problema”, diz-nos, "é que a humanidade tem a imensa capacidade de não se (des)contentar apenas com os seus velhos problemas, mas de criar permanentemente novos e de converter soluções em outros problemas" (FLORIANI, 2004, p.132).

Nesta acepção Floriani \& Knechtel (2003) propõem, então, o desafio de pensar a Educação Ambiental de modo que não esteja limitada a um enfoque naturalista do ambiente ou a um processo que destaque somente a solução de processos biofísicos.

Portanto, para além da dimensão objetiva, ou das disputas espaciais e materiais pelo acesso e uso de recursos, entendemos há também uma dimensão subjetiva, ou melhor, metapsicológica, que nos remete às distintas formas dos laços sociais, seus sentidos e significados dentro de um determinado território. Laplanche e Pontalis (2000) definem metapsicologia como o termo criado por Freud, em 1896, para designar o conjunto da sua concepção teórica, ou seja, conceitos importantes como o inconsciente, pulsão, recalcamento, sintoma, entre outros.

Cardoso (2017) nos relembra que esse termo se refere a uma das mais importantes noções do sistema de categorias psicanalíticas "a ponto de atravessar de cabo à rabo a obra freudiana, muitas vezes confundindo-se com a própria essência de seu projeto" (CARDOSO, 2017, p.16). Portanto, continua o autor, a metapsicologia constitui o sistema de pressupostos teóricos que 
organizam a experiência psicanalítica enquanto experiência e enquanto analítica, determinando a ordem de sua práxis.

Todos os conceitos, noções e categorias, as hipóteses e pressupostos que formam a metapsicologia seriam da ordem de conceitos práticos e não teoréticos. Por este ângulo, significa que todos e cada um deles não visam 'designar' sendo, portanto, carentes de denotação ou referência, constituindose em concepções que orientam e circunscrevem o âmbito de uma atividade. Logo, afirma o autor, a metapsicologia nos ajuda a colocar em primeiro plano um espaço intervalar, enfatizando que a psicanálise opera exclusivamente nesta estranha região de borda, nesta espécie de espaço fronteiriço entre os registros da natureza e da consciência, ou seja, o inconsciente (CARDOSO, 2017, p. 28).

Tomando de empréstimo, então, as reflexões do autor, podemos dizer que "algo" na crise ambiental também circunscreve um espaço de estranheza , que interroga a nossa própria existência no planeta, não nos impulsiona o suficiente para uma mudança de paradigma e, por isso, afirmamos, revela o nosso inconsciente social.

Nesse aspecto, vemos um correlato com a prática psicanalítica, pois esta nos diz que podemos escolher assumir uma posição política em relação a nossa prática social, tal qual nos ensina Freud (1916):

\begin{abstract}
quando o médico conduz o tratamento psicanalítico de um doente de nervos, seu interesse não se dirige de modo algum ao seu caráter. Primeiro ele quer saber o que significam seus sintomas, quais moções pulsionais se escondem atrás deles, por meio de que se satisfazem e quais estações do caminho mais misterioso levaram esses desejos pulsionais até esses sintomas (FREUD, 1916, p.254.).
\end{abstract}

Num alinhamento ao pensamento freudiano, estabelecemos então uma analogia com a práxis psicanalítica entendendo que é necessário escutar o que significa a degradação (sintoma) do planeta, o que se esconde por trás da manutenção dessa posição (o discurso existente) e qual a história que se conta sobre o que aconteceu (até se chegar ao estado que se está). Aliás, nisto nos alinhamos à Floriani e Knechtel (2003) acerca do saber ambiental, que "busca o que as ciências ignoram, exigindo uma negociação nos interstícios das superfícies discursivas entre si" (FLORIANI\&KNECHTEL, 2003, p.30) 
A partir dos pressupostos metapsicológicos, ou seja, da dimensão do inconsciente, que quebrar de maneira incompreensível a continuidade lógica do pensamento e dos nossos comportamentos cotidianos, que vemos como possível pesquisar e produzir experiências formativas a partir de dois campos distintos como a Educação Ambiental e a Psicanálise.

Com este percurso acreditamos incluir no debate da pedagogia ambiental, por assim dizer, um ultrapassamento às relações usuais com as ciências, possibilitando incluir novo saber. Uma inclusão - que se salienta - não deve ocorrer apenas pela construção de uma nova disciplina tal qual um retalho de patchwork, mas como nos diz Leff um "espaço no qual a criatividade do pensamento e as mudanças sociais se entrelaçam na busca de novos sentidos de civilização e de alternativas de organização para 0 desenvolvimento dos povos" (LEFF, 2011, pag.184).

No tocante ao encontro com a psicanálise, Leff, de maneira excepcional, abre-nos a essa possibilidade quando fala que "talvez seja em relação com o saber que funda suas práticas e em sua cumplicidade na subversão do conhecimento científico que se encaram de frente esses saberes". (LEFF, 1998, apud LEFF, 2011, p.188). Disso que o autor nos introduz, ou seja, essa "subversão" do conhecimento científico podemos reconhecer, inegavelmente, a psicanálise de Sigmund Freud que "operou uma ruptura com o saber existente, produziu seu próprio lugar e, epistemologicamente, não se encontra em continuidade com saber algum, apesar de arqueologicamente estar ligada a todo um conjunto de saberes sobre o homem, que se formou a partir do século XIX " (GARCIA-ROZA, 1984)".

É certo que ainda não temos as respostas para essas indagações, mas para este trabalho trazemos algumas reflexões à luz de aspectos do conceito de pulsão, uma das categorias mais importantes dentro da metapsicologia freudiana.

Inicialmente tecemos considerações sobre as questões ambientais a partir do Mal-Estar tal qual descrito por Freud em 1930; em segundo lugar, a delimitação de aspectos que, notadamente, marcam a nossa subjetividade contemporânea compondo o cenário de intervenção para a Educação Ambiental; em terceiro lugar, um pequeno recorte acerca de autores que tem 
buscado de uma maneira ou outra, relacionar as questões ambientais com a subjetividade humana. E por fim, as nossas interrogações que delimitam esse caminho em construção. Caminhemos, pois, em direção as nossas considerações.

\section{O mal-estar da civilização}

Para Freud (1930), o "mal-estar" é a dificuldade de intrínseca de vivermos no âmbito da coletividade, fato que, como já dissemos acima, nos leva às consequências de pensar a patologia mental como uma espécie de expressão do impasse no campo de alocação de posições até o limite do civilizatório, até os laços dos pertencimentos. Por isso, entendemos que há um mal-estar no que chamamos de "questões ambientais, e que, não se insurge contra nem à revelia do processo civilizatório, mas dentro dele. Para avançarmos nessa discussão é importante verificar o que Freud entende por civilização:

Civilização designa a inteira soma das realizações e instituições que afastam a nossa vida daquela dos nossos antepassados, e que servem para dois fins: a proteção do homem contra natureza e a regulamentação dos vínculos dos homens entre si. (FREUD, 1930/2010, p. 48).

A denominação de civilização utilizada por Freud nos remete ao esforço hercúleo de ultrapassar as adversidades que o próprio planeta impôs a nossa permanência enquanto humanos. Mas, se a civilização pôde favorecer o desenvolvimento de ciências e técnicas que permitiram à humanidade garantir seus domínios sobre a natureza e, inclusive, transformaram os homens em novos deuses, nos aponta Enriquez (2002) em Freud (1930) por outro lado, essa dominação se tornou causa de desilusão, pois não nos tornamos mais felizes com todo esse progresso. Em outras palavras, Freud continua, "se lembrarmos como fracassamos justamente nessa parte da prevenção do sofrimento, nasce a suspeita de que aí se esconderia um quê da natureza indomável, desta vez da nossa própria constituição psíquica (FREUD 1930/2010, p. 44). Essa natureza indomável, a qual Freud fala, introduz-nos ao conceito de pulsão: 
Chegamos assim à natureza essencial das pulsões, considerando em primeiro lugar suas principais características - sua origem em fontes de estimulação dentro do organismo e seu aparecimento como uma força constante - e disso deduzimos uma de suas outras características, a saber, que nenhuma ação de fuga prevalece contra eles. (FREUD, 1915, p. 125).

A pulsão, assim caracterizada por Freud, é um conceito que é diferente de instinto, com o qual é usualmente associada, e, portanto não tem por finalidade manter a vida, ou a auto conservação. Aliás, Garcia-roza (1986) nos ensina que, a partir da exposição de Freud (1915), a pulsão deve ser entendida como um desvio do instinto sendo "representante no psiquismo de um estimulo que ocorre num órgão ou parte do corpo e alcançam a mente como uma exigência feita à mente no sentido de trabalhar em consequência de sua ligação com o corpo". E assim, continua o autor, "ao mesmo tempo em que a pulsão representa o corpo no psiquismo ela só se faz presente neste último através de seus representantes psíquicos: a ideia (Vorstellung) e o afeto (Affekt) (GARCIA-ROZA, 1986, p.16)".

Sobre esse ponto Enriquez (2002) nos relembra ainda, que no MalEstar da Civilização, essa obra tão cara à Freud, há a introdução do conceito de pulsão de morte que reforça os aspectos interditores no domínio da civilização e, portanto, reitera o autor, o pulsional faz parte do fundamento de cada sujeito e do fundamento da vida social.

Visto que essa parte da psicanálise freudiana requer maior tempo de exposição para clarificação - não sendo objeto desse trabalho - demarcamos, no entanto, a importância desse conceito no sentido posto por Zygouris (1999) " é no entanto, a noção de pulsão que permite aproximar as tensões de vida no corpo erótico que sofre, tomado por seus impedimentos e criações endógenas, mesmo que suas causas sejam de ordem exógena ( a história , o meio social, os traumas, as relações precoces com o outro, etc.). ZYGOURIS (1999, p.7).

É nesse ponto que assumimos que há sem dúvida, uma direção para identificação de um mal-estar quando falamos em meio ambiente no sentido freudiano, desvelado na existência de uma dissonância entre as exigências da pulsão e da civilização.

A psicanálise, nesse sentido, pode nos dizer que, talvez, até o momento, a Educação Ambiental não tenha tematizado, de forma suficientemente clara, a 
dimensão pulsional do ser humano na sua relação com o meio ambiente. Ainda que consideremos um sujeito do inconsciente constituído pelas leis da cultura/civilização, existe algo atuante em si que não se harmoniza, tornandose permanente o desassossego, algo que encontra no registro das pulsões. Ou ainda, a cada movimento que a civilização faz no sentido do seu aprimoramento, traz consigo aquilo que é da ordem do primitivo, ou seja, um resto pulsional.

É dessa perspectiva, ou seja, a partir das pulsões que nos constituem enquanto sujeitos e que nos desnaturalizam, portanto, que entendemos que devemos lançar o olhar acerca do modo como lidamos com o meio ambiente, compondo assim o quadro com o desvelamento sobre nossos pertencimentos sociais, ou melhor, acerca da fragilidade das nossas relações.

Tarefa como já dissemos, nada fácil, mas o fato é que há em curso não somente uma catástrofe ecológica, mas um adoecimento dos laços sociais que se expressa numa grande massa de excluídos do sistema social vigente. $\mathrm{Na}$ realidade esses dois aspectos, os excluídos e a crise se configuram com um sistema único, ou seja, a crise social também se constitui numa tragédia ecológica com temas que se entrelaçam de forma inexorável: corrupção, violência e destruição ambiental inigualável.

Não causa espanto, desta forma, os mais de 3,5 bilhões de seres humanos que sofrem com mudanças climáticas e suas terríveis consequências; que assistem ao consumo exacerbado - a forma de gozo do sujeito modernode uma minoria, flagelam em ambientes de grande adversidade, curvam-se diante de um sistema econômico que perpetua a desigualdade, num grande sofrimento físico e psíquico sem precedentes.

Noutra perspectiva também podemos nos reportar aos crimes ocultos da escravidão humana e da destruição ambiental não apenas inextricavelmente ligados, mas impulsionados mutuamente, nos prova Bales (2016). Os escravos modernos, conclui tristemente o autor, são usados para destruir o meio ambiente e a destruição associada à escravidão é o motor que alimenta o mercado global do que comemos e utilizamos como os despojos de um crime, todos os dias.

Apropriamo-nos das palavras de Eliane Brum em sua fala sobre o crime ambiental ocorrido em Mariana como uma analogia a isso que expomos: 
Como não pensar, a cada dia, que a lama avança. Essa lama tóxica que mata gente, mata bicho, mata planta, mata histórias. Essa lama que engoliu um povoado chamado Bento Rodrigues assassina o Rio Doce, avança pelo oceano, atravessa os estados e segue avançando. Essa lama que deixou meio milhão sem água. Essa lama venenosa que vai comendo o mundo como se fosse um organismo vivo. Essa lama morta que se move. $\mathrm{E}$ ao se mover, mata. Enquanto alguém toma um café, pega o ônibus, reclama do trânsito, faz um selfie, se apaixona, assiste a uma série do Netflix, se preocupa com as contas, faz sexo, se queixa do chefe, sente que o cotidiano não está à altura de suas grandes esperanças, briga no Facebook, faz planos para as festas de fim de ano, engole umas gotas de Rivotril, a lama avança. Enquanto escrevo, a lama avança. Piscamos, e a lama avança. Parece quase impossível pensar em algo além de que a lama avança. $E$ ninguém pode afirmar até aonde a lama vai chegar. (EL PAÍS, 2015³).

Em suas palavras a jornalista nomeia, numa designação quase poética, essa relação entre flagelo ambiental, impotência, passividade, negação sofrimento e desamparo que nos assola no cenário ambiental. Há uma espécie de desvio da civilização em relação ao seu curso "que se estabelece e se mantém entretendo e aumentando considerável e inevitavelmente em seu seio uma força destrutiva" (RAULET, 2002, p.76). Em nossa compreensão, ou seja, o caminhar de nossa cultura tem mostrado violência, sofrimento e destruição onde de um lado há aumento de riquezas, de benesses; por outro, constitui-se também miserável, desumana, bárbara, trazendo o componente primitivo das pulsões que desnudam o que há de recalcado: a miséria, a falta de humanidade, a barbárie.

Retornamos ao ponto inicial de nossa discussão reiterando que não há dúvidas de que reside um Mal-Estar, no sentido freudiano na crise ambiental, pois é preciso denotar que ela também retorna a nós, sujeitos, enquanto uma questão sobre o sentido das nossas ações ou "nosso jeito de andar e habitar o mundo", insistentemente nos tem nos alertado Leff (2006).

Desta feita, podemos dizer que a crise interpela os sujeitos como àqueles capazes de responder sobre o sentido das suas atividades, ou seja , uma dimensão ética, ponto a considerarmos acerca desse encontro entre a EA e a psicanálise no sentido que "algo" possa ser desvelado, pois a crise, irredutível a um processo físico, porta uma verdade sobre nós, pois tudo também são obras nossas.

\footnotetext{
${ }^{3}$ Disponível em: https://brasil.elpais.com/brasil/2015/11/30/opinion/1448893478 611214.html.
} 


\section{A subjetividade contemporânea}

Avançando, distinguimos que há no bojo da civilização algo da ordem de um fracasso que denuncia a extensão do desamparo a que estamos submetidos quando circunscrevemos a questão ambiental no seu amplo espectro e por isso para compor nosso campo reflexivo trazemos alguns elementos acerca da nossa subjetividade contemporânea.

Elisabeth Roudinesco, historiadora e psicanalista, diz-nos que moldam essa subjetividade a morte, as paixões, a sexualidade, a loucura, 0 inconsciente e a relação com o outro (ROUDINESCO, 2000).

É no seio dessa subjetividade, então, que Dunker (2011) identifica a modernidade e seus modos de subjetivação como compostos por narrativas, discursos e teorias acerca da 'perda da experiência' ou seja: a incapacidade do sujeito de se reconhecer em sua própria história particular ou, ainda, a dificuldade de estabelecer formas sociais universalmente compartilháveis. Leciona o autor que, nesse aspecto, a alienação seria uma figura fundamental de nomeação desses "bloqueios da experiência".

O autor nos conduz além nesse raciocínio, ao fazer uma analogia às personagens como Hamlet, Dom Quixote, Dom Juan, Robinson Crusoé e Fausto, assumindo que estes podem ser tomados como exemplos de narrativas cruciais quando se pensa no tipo de subjetividade que caracteriza essa modernidade. Cada um desses heróis, continua Dunker, em cada caso de maneira distinta, está exclusiva e egoisticamente interessado em seus empreendimentos pessoais, seus atos e suas obras, fazendo-se reconhecer por seu desejo, definindo-se pelo tipo de divisão subjetiva que Ihes caracteriza. Assumimos com essa proposição de Dunker que esta é também uma fórmula bastante próxima utilizada por Leff quando diz:

La problemática ambiental emerge como una crisis de civilización: de la cultura occidental; de la racionalidad de la modernidad; de la economia del mundo globalizado. No es una catástrofe ecológica ni um simple desequilibrio de la economía. (...) es la pérdida del sentido de la existencia que genera el pensamiento racional en su negación de la otredad (LEFF, 2004, p.9.).

Se nossa 'crise ambiental' deve ser compreendida, como assinala Leff no trecho que acabamos de citar, como uma 'crise de civilização' estreitamente 
associada a uma suposta 'perda do sentido da existência', assim como a certas formas de 'negação da alteridade', então ela essencialmente reforça o campo de nossos afetos.

Uma série na qual deveríamos acrescentar um processo de ordem propriamente metapsicológica que, justamente, a psicanálise é capaz de isolar. A poesia da psicanalista Maria Rita Kehl ilustra muito bem isso ao se referir às reservas naturais como "(...) reservas de mistério, de desconhecido, reservas para nosso fascínio e nosso medo. Reservas de escuridão. Reservas de humildade, onde devemos ser lembrados da insignificância de nossa condição no universo. Reservas de instintos, de pulsões, de fúria, de desamparo" (KEHL, $\left.1989^{4}\right)$.

Os traços, as marcas dessa nossa subjetividade então compõem esse cenário delimitando a estreita, delicada e complexa relação entre os limites do planeta, a sociedade moderna marcada por um estímulo incessante ao direito ao prazer e ao entretenimento, alienada bem como por uma classe de excluídos em crescente maioria. Cenário onde, pelos fundamentos do conceito de pulsão, a harmonia com o registro da civilização não é possível.

\section{Diálogos em construção}

Dentre nossas tarefas para pensar esse encontro entre a EA e a psicanálise está a delimitação de um marco teórico porém, as inquietações sobre como lidar com a subjetividade humana e as questões ambientais não tem sido tema usualmente abordado pelos psicanalistas e nem pela Educação Ambiental. Podemos dizer que esse ainda é um dialogo a construir, onde denotamos uma transformação em curso, como podemos ver a seguir.

Freud não buscou se ocupar diretamente das questões ambientais e nem da educação, no entanto em sua obra perpassam as indagações e constatações sobre a complexidade da sociedade atual expressa com ênfase nos textos Atos Obsessivos e Práticas Religiosas (1907), Doença Nervosa Moderna e Moral Sexual Civilizada (1908), Totem e Tabu (1912), Psicologia

${ }_{4}$ Disponível em: https://blogdaboitempo.com.br/2011/05/30/reservas-ambientais-reservas-doimaginario/. Acesso em: 08 de setembro de 2018. 
das Massas e Análise do Eu (1920), Futuro de Uma llusão (1927)) e, finalmente, Mal-Estar da Civilização (1930) e Por que a Guerra (1932).

No começo dos anos sessenta, tem-se o trabalho do psiquiatra e psiquiatra americano Harold Searles, “O ambiente não humano”, livro de 1960. O tema se expressa no fato de que o ambiente - não -humano-, constitui-se como um dos mais importantes ingredientes da existência psicológica humana e que também se articula como uma fonte ambivalente de sentimentos, pois há uma tentativa de se ignorar a sua importância, mesmo diante de seu bem-estar psicológico. Relembramos aqui que a década de 50 e 60, época em Searles consolida sua clínica nos Estados Unidos, o surgimento da importante figura de Rachel Carson, já bastante conhecida, ao desenvolver e acompanhar as questões ambientais no país, especialmente aquelas relacionadas à contaminação de ambientes por agrotóxicos.

Searles, já em 1972, escreve o artigo chamado "Processos inconscientes da crise ambiental" onde afirmava que o estado atual da deterioração ecológica é tal que provoca ansiedades sendo que estas são inconscientes e de diferentes variedades como características dos vários níveis da história do desenvolvimento do ego de um indivíduo. Como por exemplo, a apatia, diz-nos o autor, que seria uma defesa do ego, amplamente inconsciente, contra a ansiedade causada pela degradação.

A partir da década de 1980 começam a aparecer alguns estudos sobre a articulação direta entre os processos do inconsciente e a crise ambiental, principalmente a partir de psicanalistas europeus. Assim como a figura de Rachel Carson se impôs na América dos anos 50 e 60, a partir da década de 70 e 80 há uma forte mobilização mundial em defesa das questões ambientais. Nesse caso afirmamos com mais segurança, que a participação de ao menos uma parte do movimento psicanalítico nesse momento, literalmente marca uma tentativa de inserção nas discussões ambientais, no entanto, sabe-se que de ambas as partes, essa aproximação não é de todo fácil.

Nesse momento em particular destaca-se, então, uma conferência realizada pelo Freud Museum, em Londres, 1992, intitulada "Pensamentos Introdutórios sobre a Loucura Ecológica”, promovida pelo seu diretor Ivan Ward. A conferência expressou as dúvidas sobre os argumentos recorrentes acerca do domínio adequado da psicanálise como uma teoria e terapia, 
enquanto uma comunicação intersubjetiva entre paciente e terapeuta e as suas relações com as questões ambientais. Essa foi uma clara tentativa de estimular o pensamento e causar algum impacto na forma como o debate é conduzido pela psicanálise, criando diferentes caminhos. Finalizava o autor:

\begin{abstract}
Instead of arguing for a change of behaviour through the methods of 'conditioning' - changing the system of rewards and punishments which govern our manifest behaviour -we were arguing for an analytic attitude. Psychoanalysis is essentially a self reflexive discipline. Is it possible to change behaviour through understanding ourselves better - our hopes and wishes, and more especially our fears - and so loosen the chains which bind us to a way of life that has endangered not only ourselves, but future generations? ${ }^{5}$ (WARD, 1992, p.10).
\end{abstract}

Em 2001 Shierry Weber Nicholson publica o livro "O amor à natureza e o fim do mundo: as dimensões não ditas acerca da questão ambiental" (The Love of Nature and the End of the World: The Unspoken Dimensions of Environmental Concern (2002) que aborda o tema por um viés mais político, através do que chama de "bloqueios psicológicos"). Fundamentada em autores como Harold Searles, Wilfred Bion, bem como de Donald Meltzer e D.W. Winnicott assim como diversos filósofos, entre eles Merleau-Ponty, propõe que uma resposta eficaz ao ecocídio catastrófico seria reconhecer a destruição do nosso modo de vida atual e nossa própria implicação profunda no processo social global.

Segundo Nicholson então essa consciência é dolorosa e angustiante podendo suscitar sentimentos de medo, ansiedade e culpa tão ameaçadores que provocam todas as nossas defesas psíquicas: evitamos essa consciência reprimindo-a e evitando-a, ou projetando.

Na América Latina, em 1998, Leff (2011) numa conferência apresentada no Primeiro Encontro Latino Americano de Psicologia Ambiental aponta a possibilidade do encontro do encontro do saber ambiental com a psicanálise. Leff, na admirável força do desejo de construir uma interlocução com novas fronteiras do pensamento traz o mais importante reatualizador de

\footnotetext{
${ }^{5} \mathrm{Em}$ vez de argumentar por uma mudança de comportamento através dos métodos de" condicionamento "_ ou seja, mudar o sistema de recompensas e punições que governam nosso comportamento manifesto - defendemos uma atitude analítica. A psicanálise é essencialmente uma disciplina auto-reflexiva. É possível mudar o comportamento através do entendimento melhor de nossas esperanças e desejos, e mais especialmente nossos medos e afrouxar as cadeias que nos unem a um modo de vida que ameaça não só a nós mesmos, mas às gerações futuras? (tradução da autora).
} 
Freud, Jacques Lacan, para propor que esse encontro se "apresente num espaço que não é o da complementaridade nem da articulação de seus saberes, mas de seus paralelismos, suas solidariedades e suas disjunções" (LEFF,1998, apud LEFF, 2011,p.).

A partir da metade dos anos 2000 há uma demanda que vem do próprio movimento ambiental ligado à conservação e proteção da vida selvagem. Neste sentido, inicia-se uma aproximação com a ciência comportamental (behaviorista) numa tentativa de diminuir o potencial de escolha de produtos oriundos do tráfico de animais selvagens (Broad 2016; Burgess, 2013)).

A outra abordagem também mais recente se situa em relação às mudanças climáticas, principalmente no tocante aos sentimentos de medo e apatia que o tema tem suscitado. Seguem-se então publicações sobre o assunto, que tem uma especificidade de se localizarem mais no âmbito do território americano e de serem provenientes de autores que não necessariamente são psicanalistas, mas que se apropriam da abordagem para suas reflexões. Destaca-se os livros de Mary-Jayne Rust "Climate on the Couch" (Rust, 2007); Rosemary Randall, "A New Climate for Psychotherapy?" (2005) e "Loss and Climate Change" (2009).

Em 2010 Joseph Dodds, psicanalista membro da Psychoanalytical Society de Praga e da International Psychoanalytical Association lança o livro "Psychoanalysis and ecology at the edge of chaos: Complexitytheory, DeleuzeGuattari and psychoanalysis for à climate in crisis." O livro sugere vários campos e ramos de estudos psicológicos que servem a uma interlocução entre meio ambiente, - ecopsicologia, psicanálise, teoria do caos, apropriando-se também do pensamento de Deleuze e Guattari, em um reconhecimento que uma abordagem única é adequada para enfrentar as crises humano-ecológicas que se impõem na atualidade.

No território americano há o destaque para a pesquisadora Renné Lertzaman, especialista em comunicação estratégica, que tem um foco nas dimensões psicológicas das mudanças climáticas e como se articulam sobremaneira com a comunicação. Em 2015 lançou seu primeiro livro intulado "Environmental Melancholia: Psychoanalytic Dimensions of Engagement" que busca correlacionar o que chama de "Mito da Apatia" vigente em relação às 
mudanças climáticas com a necessidade de se criar novos modelos de engajamento, a partir de elementos da vida psíquica.

Dessa primeira aproximação com a literatura pertinente ao tema, percebe-se de imediato é que há um movimento por parte da própria comunidade psicanalítica para lidar com as questões ambientais, mas, por outro, evidencia a ausência (ou relutância?) do movimento ambientalista para buscar essa ou mesmo outras abordagens como ponto de intersecção para novas formas de lidar com os desafios que o meio ambiente impõe. Essa é uma lacuna importante a ser evidenciada.

\section{Algumas considerações finais}

A nossa tentativa ao longo desse trabalho foi de trazer alguns elementos que pautem o diálogo entre a Psicanálise e a Educação Ambiental. Para isso nos apoiamos em apresentar alguns pontos da metapsicologia freudiana, delimitando a dimensão do inconsciente na relação do processo civilizatório com o meio ambiente, que nos causa estranheza e mal-estar .

Outro registro que compôs o nosso cenário são as características da nossa subjetividade contemporânea a nos confirmar que a experiência do homem, enquanto homem em crise, expressa na sua relação com o meio ambiente um evidente conflito. A crise ambiental claramente não é oriunda da natureza, mas sim uma expressão da natureza problemática do homem nesse dado momento da sua história.

De forma não menos importante podemos notar esses elementos, ainda que de forma não sistemática e não linear, diversos pesquisadores têm procurado olhar para as questões ambientais na expressão da subjetividade contemporânea, buscando se ancorar em diversas formas de abordagem do espectro da psicologia. No entanto uma abordagem a partir da metapsicologia freudiana ainda são escassos, ou mesmo inexistentes, o que amplia o nosso desafio na construção desse diálogo.

Nesse percurso a psicanalise nos propõe a realizarmos uma escuta sobre o sentido da interrogação que a crise ambiental nos propõe. Além disso, é preciso marcar que esta crise retorna para nós como um enigma, então, acerca do sentido das nossas ações, interpelando-nos como sujeitos, aqueles que são capazes de responder sobre o sentido das suas atividades. 
Há que pensarmos sobre as nossas atividades de trabalho, algo tão tipicamente humano e que perderam a sua finalidade de servir à vida. Aliás, muito pelo contrário, podemos afirmar que essas atividades a tem ameaçado à vida- cada vez mais, num processo que acaba por nos conduzir a negação de nós mesmos, uma vez que "mesmo sabendo disso, continuamos a fazer, mesmo a despeito do sofrimento gerado a quem quer que seja. Logo, não somente aquilo que organiza a nossa forma de vida está completamente em desacordo com o mundo como também é um desacordo com ela mesma.

A crise ambiental, portanto, tem algo de sintomático nesse sentido, ou seja: é um processo que está perdendo seu sentido humano, mas mesmo assim não conseguimos evitar reproduzir. Se a crise reflete o sujeito, reflete um processo político e, portanto, é uma questão ética, o que em sentido analítico é tal qual um sintoma (FARIAS,2017).

Essa é a dimensão que interessa à psicanálise e é onde pode dialogar com as disciplinas, nesse caso a Educação Ambiental, que reconhecem que essa crise ultrapassa ou é irredutível a um processo físico, como nos disse Floriani \& Knechtel (2003) quando nos aponta sobre um dos desafios da Educação Ambiental.

Como intervir nisso? É verdade que é preciso pensar outra educação, pois se a educação como um processo cognitivo concerne o que podemos saber disso, todavia saber disso sido pouco eficaz em alterar a atual realidade.

A nossa interrogação final se refere a pensar qual pedagogia é necessária, de um modelo que não seja nem cognitivista nem iluminista, ou seja: que não seja apenas um aumento da nossa capacidade de compreensão do que estamos fazendo, por que se compreendemos o que estamos fazendo deveríamos conseguir evitar, mas tal não acontece.

Nesse aspecto seguiremos alinhados com Floriani \& Knechtel (2003) que nos relembram a importância de uma epistemologia da Educação Ambiental essencialmente crítica, constituindo-se objeto permanente de estudos e modificações, exigindo novas metodologias ( FLORIANI \& KNECHTEL,2003, p.56).Nos elementos que uma leitura psicanalítica possa revelar talvez seja possível nos inspirarmos à transmissão de uma atitude sensível aos diferentes jeitos sobre como nos relacionamos com o planeta, 
ancorando nessa transmissão também consequências para o campo da educação ambiental

\section{Referências}

BALES, K. Blood and earth: modern slavery, ecocide, and the secret to saving the world. House LLC, New York.First edition. Random House. 2016.

BROAD, S. BURGESS, G. Synthetic biolology, product substituition and the battle against ilegal wildlife trade . TRAFFIC Bulletin, 28(1)22-28. 2016.Disponível em : https://www.traffic.org/site/assets/files/5736/traffic pub bulletin 28 1.pdf.

Acesso em 10 agosto 2018.

BURGUESS, G; COMPTON, J. Editorial. TRAFFIC Bulletin, 25:(2):41. TRAFFIC, Cambrige, UK.2013. Disponível em : https://www.traffic.org/site/assets/files/3002/traffic pub bulletin 252 editorial. pdf. Acesso em 10 de agosto de 2018.

DUNKER, C. Mal-estar, sofrimento e sintoma: releitura da diagnóstica lacaniana a partir do perspectivismo animista. Tempo Social, São Paulo, v. 23, n. 1 , p. 115-136, jan. 2011. Disponível em: http://www.revistas.usp.br/ts/article/view/12654. Acesso em 05 agosto 2018.

ENRIQUEZ, E. Da horda ao estado - psicanálise do vínculo social. Rio de Janeiro: Jorge Zahar Ed., 1991.

FARIAS, A.L. A emergência do saber ambiental numa perspectiva psicanalítica. In: EPEA 2017- Encontro Paranaense de Educação Ambiental, 2017, CURITIBA. Anais do XVI Encontro Paranaense de Educação Ambiental, 2017.

FLORIANI, Dimas. Conhecimento, meio ambiente \& globalização. Curitiba: Juruá, 2004.

FLORIANI,D.; KNECHTEL, M.Rosário. Educação ambiental, epistemologia e metodologias. Curitiba: Vicentina, 2003.

FREUD, Sigmund. Artigos Sobre Metapsicologia. In: A História do Movimento Psicanalítico, Artigos sobre Metapsicologia e Outros Trabalhos (1914-1916). Rio de Janeiro: Editora Imago. 1996.

FREUD, Sigmund. Alguns tipos de caráter encontrados na prática psicanalítica (1916). Sigmund Freud; tradução de Paulo Cesar de Souza. São Paulo: Companhia das Letras 2010.

FREUD, Sigmund. O mal-estar na civilização: novas conferências introdutórias à psicanálise e outros textos (1930-1936). Sigmund Freud; tradução de Paulo Cesar de Souza. São Paulo: Companhia das Letras 2010. 
GARCIA-ROZA, L. A. Freud e o inconsciente. 15. ed. Rio de Janeiro: Jorge Zahar Ed., 1984.

LAPLANCHE, J; PONTALIS, J. B. Vocabulário da Psicanálise. São Paulo: Martins Fontes, 2000.

LASCH, C. O mínimo eu: sobrevivência psíquica em tempos difíceis; trad. J.R. Martins F. 4.ed. São Paulo: Brasiliense, 1987.

LEFF, E. Racionalidad ambiental: la reapropiación social de la naturaleza, México, Siglo XXI editores.2004.

LEFF, E. Aventuras de la epistemologia ambiental. México: Siglo XXI, Editores, 2006.

LEFF, E. Saber ambiental: sustentabilidade, racionalidade, complexidade, poder. Petrópolis, RJ: Ed. Vozes, 2011.

NICHOLSEN, S. The Love of Nature and the End of the World: The Unspoken Dimensions of Environmental Concern. Cambridge, MA: MIT. Press 2001.

RAULET, G. As duas faces da morte. Sobre o estatuto da agressividade e da pulsão de morte em 0 mal-estar na civilização. Em torno do mal-estar na cultura, de Freud-Jacques Le Rider, Michel Plon, Gèrard Raulet,Henri ReyFlaud.São Paulo: Escuta. 2002.

ROUDINESCO, Elisabeth. Por que a psicanálise? Rio de Janeiro: Jorge Zahar. 2000.

SEARLES, Harold. The nonhum an environment In normal development and in schizophrenia. New York: International Universities Press, Inc. 1960.

SEARLES, Harold. Unconscious processes in relation to the environmental crisis, The Psychoanalytic Review. 1972.

ZYGOURIS, R. Pulsões de vida. São Paulo: Escuta, 1999. 